\title{
Covid-19: BMA calls for rapid testing and appropriate protective equipment for doctors
}

\author{
Abi Rimmer
}

The BMJ

The BMA has said that it is working to ensure that all doctors have appropriate protective equipment and that those who are self-isolating with minor respiratory symptoms have access to rapid testing.

In a letter sent to BMA members on 16 March, BMA council chair Chaand Nagpaul said that, in response to the covid-19 pandemic, the association was working to tackle the issues affecting doctors, across the nations, and in each branch of practice.

"We will all be naturally worried about how this will impact on our ability to provide vital care for patients," Nagpaul said. "We are also concerned about the need for healthcare workers to be protected from exposure so that we are able to work as safely and effectively as possible throughout the duration of this crisis."

Nagpaul said that the government needed to be open and transparent about its approach, modelling, and plans to combat this epidemic. He said that the BMA was working to establish and secure information and assurances on a range of issues, including "adequate and appropriate personal protective equipment [PPE] for both hospitals and general practice so that doctors can be protected as best as possible from becoming infected."

The association is also seeking "rapid testing of doctors and other health professionals who are self-isolating due to minor respiratory symptoms, so that those who are covid-19 negative and recover sooner than seven days can return to work," Nagaul said. And it is seeking clarity over government plans to increase critical care capacity, as well as details of how retired doctors will be able to provide medical care.

The UK's training bodies have said that during the pandemic trainees could be deployed to areas of major clinical need. ${ }^{1}$ Nagpaul said that the BMA was seeking answers regarding what support, training, and indemnity would be provided to them, as well as reassurances about how these measures would affect junior doctors and their training.

"In addition, we are compiling a list of contractual issues affecting doctors in all branches of practices, which we will call upon relevant authorities in each nation to address," Nagpaul said. "We are also in dialogue with the General Medical Council and are calling on it to enable flexibility in relation to annual appraisals and revalidation, to ensure those ultimately tasked with working outside their normal scope of practice can do so without fear of regulatory reprisals and to do all it can to allow students and trainees to progress through training."

Nagpaul reminded members that the BMA has a range of wellbeing services including 24/7 counselling, available to all doctors and medical students free of charge. "Remember we are here to represent you, to support you to address any professional and workplace challenges that you may face, and to help you through what is clearly going to be a very difficult time for all of us," he said.

Rimmer A. Covid-19: trainees will not move jobs in April. BMJ 2020;368:m1088. Published by the BMJ Publishing Group Limited. For permission to use (where not already granted under a licence) please go to http://group.bmj.com/group/rights-licensing/ permissions 